\title{
Using Aesthetic Response - A Poetic Inquiry to Expand Knowing, Part I: The Rx6-Method
}

\author{
Anna Gerge ${ }^{1 *}$, Margareta Wärja ${ }^{123}$, Inge Nygaard Pedersen ${ }^{1}$ \\ 1 Doctoral Programme in Music Therapy, Department of Communication and Psychology, Faculty of \\ Humanities, Aalborg University, Denmark \\ 2 Department of Clinical Cancer Epidemiology, Karolinska Institute, Sweden \\ 3 Expressive Arts Institute Stockholm, Sweden \\ *anna@insidan.se
}

Received: 2 September 2016 ; Accepted: 13 February 2017 ; Published: 1 March 2017

\begin{abstract}
A step-wise research procedure of arts-based research (ABR) called the Rx6 method is presented. This ABR method is informed by expressive arts therapy, heuristic inquiry, attachment theory, and contemporary affective neuroscience, and is aimed at deepening the understanding of embodied felt sense. The Rx6 approach is based in aesthetics and a pragmatic pre-understanding inspired from an interpretive and a constructivist tradition. The method is a heuristic endeavour where art is applied towards the creation of meaning. For the purpose of exemplifying this method, artwork, produced within the context of a randomized control trial as part of a mixed methods study involving women treated for gynaecological cancer was used. Response art consisting of short written aesthetic responses to pictorial artifacts was applied in a structured manner. The data provided a rich artistic material in which to dialogue with artifacts in search of a condensed response statement. The Rx6 method involves six steps: to relate, resonate, respond, reflect and react to results. Engaging in ABR can offer clinicians and researchers a deepened, expanded, and embodied understanding of the studied phenomena. The complexity of sharing implicit processes and tacit knowledge, its caveats and gains, along with theoretical perspectives of such undertakings, are presented and discussed.
\end{abstract}

Keywords: Neurobiology of intersubjectivity, embodiment, felt sense, experience

\section{Introduction}

The purpose of this article is to describe and offer a rationale for a step-wise research procedure of arts-based research (ABR) developed by the two first authors to be implemented in clinical work or research. How this method can be applied will be exemplified by presenting excerpts of our own aesthetic responses to pictorial artifacts produced by 57 research participants in a randomized controlled trial developed by Wärja, Bergmark, and Bonde (2012). The Ethics Board of Karolinska Institute, Stockholm, Sweden granted ethical approval on January 19, 2012 (ref. 2012/5:1). An artifact is defined here as an object produced or shaped by human craft, conception, and agency (Gerge, 2016). The method was developed to provide a richer account of the qualitative analyses of the research subjects' written statements on how they experienced their bodies after being treated for gynaecological cancer. The study of Wärja 


\section{Epistomology: A Combination of Interpretivism and Positivism}

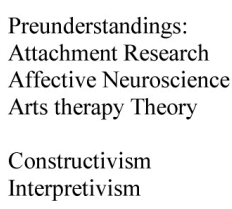

\section{Methodology:}

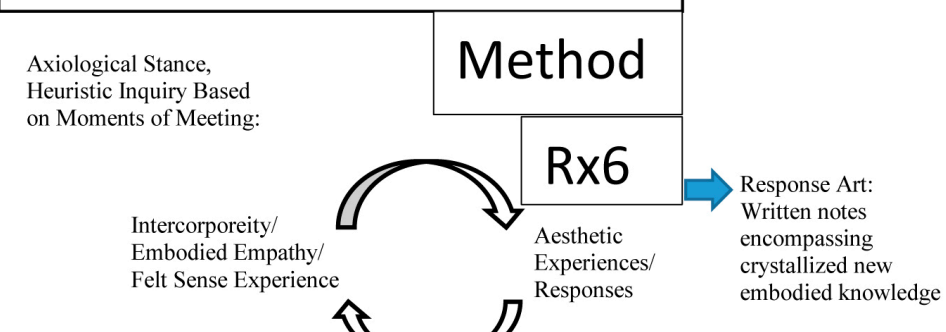

Figure 1. The inquiry from epistemology to methodology and method (Gerge, 2016).

The structured and time-framed methodology presented here - the Rx6-method - is offered as a contribution to the growing field of arts-based research (Leavy, 2015). In addition, we mean that this method can enhance research rigor, which has been addressed and called for in order to develop the ABR tradition (Forinash, 2016)

(2012a, 2012b) was designed with specific clinical purposes in mind, one was to analyze differences in the paintings between the three different time points

According to Viega, (2016b) scientific rigor in ABR means that, "methods, design, and results should be grounded in the purpose of inquiry" (p. 8), which here was to delve into pre-existing research material. In line with Viega's thinking on ABR as "a methodology steeped on aesthetics" (p. 5), we offer an artistic method, Rx6, which is informed by theoretical perspectives of both heuristic inquiry, expressive arts therapy, attachment research, contemporary research on the neurobiology of inter-subjectivity and embodiment. For a theoretical deepening of the method, see Gerge, Wärja, and Pedersen (2017). The use of response art in the present inquiry is the primary method (Austin \& Forinash, 2005; Viega 2016a, 2016b) we used to discern important avenues of the pre-existing data of gathered pictorial artifacts.

We agree with Rolling (2013) that ABR neither is wholly quantitative nor qualitative. Being precise with nuances and the use of perception is of value in both heuristic research (Gerge, 2016) and in a variety of arts-based inquiries and qualitative research. The life world of each individual is unique; a hermeneutic approach might be the most respectful undertaking in the attempt to try to understand as fully as possible another human being. Though the principles for experiencing and relating to the world can be generalized, as we share common ways to perceive and make sense of our experiencing, see figure 1, adapted from Gerge.

\section{Defining Arts-based Research}

One definition of ABR was given by Austin and Forinash (2005) as "Art forms ... are essential to the research process itself and central in formulating the research question, generating data, analyzing data, and presenting the research results" (p. 459). Leavy (2009) defined ABR as "a set of methodological tools used by qualitative researchers across the disciplines during all phases of social research, including data collection, analysis, and representation" (p. ix). Later (Leavy, 2015), she highlighted the value of researching these realms with methods that make sense to tacit knowledge and included a participatory perspective. Such endeavor can preferably be explored in qualitative or arts-based studies. In line with Barone and Eisner (2012), Viega \& Forinash (2016) defined ABR as an umbrella term for the use of the arts as a research method. The latter specified that ABR could be applied as a method where "the art forms are primary in the research process - and as an overall methodology - where a creative worldview forms the philosophical foundation for an inquiry" (p. 491). These authors 
underlined that in $\mathrm{ABR}$, the arts inform and sometimes lead the research process. ABR can be one part of the research process or the main research method (Leavy, 2015; Viega \& Forinash, 2016; Viega, 2016b). Viega and Forinash (2016) provided a compilation on variations in ABR in relation to music therapy. They also highlighted the favourable position of creative arts therapists in embracing an arts-based inquiry and pointed out the many ways ABR and clinical practice are intertwined and can crossfertilize each other. According to Leavy $(2015$, p. 20) an artistic method can serve as an entire methodology in a study, for examples see Ledger and McCaffrey (2015).

\section{The Implicitly Known as a Source of Information}

McNiff $(1998,2011)$ made important introductions to arts-based inquiries. "Knowing through the arts takes place in ways that are distinctly different, yet complementary to rational cognition" (McNiff, 2008, p. 30), a statement further elaborated by (Sajnani, Marxen, \& Zarate, 2017; Wiedenhofer, 2017). A theoretical understanding underpinning our perspective is given by contemporary affective neuroscience (Cozolino, 2002; LeDoux, 1996; Siegel, 2010) and relational psychodynamics (Lyons-Ruth, 1999). According to Lyons-Ruth et al. (1998). Such knowledge is distinct from that which is possible to verbalize and derives from the dynamic unconscious. ABR offers both a heuristic (Douglass \& Moustakas, 1985; Moustakas, 1990, 1994), empirical and thorough artistic opportunity to engage in a dialogue with a statement, an expression, or a piece of artwork, and answers at the same level of implicit knowing in which that artpiece was done. Then depth can answer to depth (Gerge, 2016; Knill, Levine \& Levine, 2004).

When studying the psychological responses to artistic experiences and expressions both an expressive and a receptive aesthetic response can be conceptualized and used. Then aesthetic responses can be performed in all kinds of artistic modalities and methods and can work together with other research methods. Sajnani et al. (2017) proposed an ethical responsibility as a way to recognize and respond on how social injustice influences lives. For such an endeavour we need tools to reach and come close to the life-worlds of others. In music therapy, critical social aesthetics (CSA) described by Sajnani et al. (2017) is where critical social theory, music aesthetics and improvisation-based music therapy are combined. Though of course self-dialogue, diary writing, poetic inquiry, and all other arts modalities and intermodal transfer can be involved in such inquiry of $A B R$ and thus lead to an enhanced and nuanced understanding. The importance of aesthetic and relational aspects in human appraisal processes, including therapy and research, cannot be over-estimated. Nor can the intermodal transfer which refers to the fact that imagery/imaginative processes are experienced in multimodal ways and that moving between art forms might deepen and open up to enhanced implicit processing (Gerge, 2010; Knill et al.,1995).

\section{The Need of Tools Addressing Implicit Domains}

An essential part of ABR is to allow oneself to become affected on a profound level when researching health processes. We even mean it is a necessary component when engaged in arts-based research methods and in psychotherapeutic processes utilizing altered state of consciousness (ASC), states of daydreaming where messages from the unconscious can more easily come through. As Gilroy $(2012$, p. 12) stated, in the art/ arts therapies there might be an absence of evidence but a presence of knowledge. This is partly due to the nature of tacit knowledge (Polanyi, 1958). Polanyi affirmed that we could know more than we can tell. Even if tacit knowledge is part of everyone's daily life, it is not easily shared, nor easily articulated. It consists of embodied memories and schemes, which are implicitly ingrained in us and which we often take for granted. Thus, methods that delve into the implicit realms of knowing are of certain interest in researching subjective experience and especially expressions of art/arts in therapy. Arts-based research is a valuable way to gain insights, not knowable by other means, and/or to enrich the understanding of data. McNiff (2011) described ABR as 
"especially significant" to the arts therapies, which use creative expression as a "way of knowing, communicating, and furthering personal and social development" (p. 387). According to Leavy (2015), ABR can poignantly add to consciousness-raising, emancipatory, and transdisciplinary research (p. 294). The perceptual openness potentially achieved might activate our mirror neurons (Gallese, 2009; Gallese \& Ferri, 2014; Wiedenhofer, 2017). The latter highlights the embodied aesthetics including the active (expression) and the receptive (impression) side of the aesthetic experience. In using the Rx6 method we suggest a simple, easy to follow, clear structure for this.

\section{The Rx6-method: Accessible for All}

The Rx6 method is well suited for creative arts therapists, both for experienced researchers and for newcomers to the field, for psychologists, psychotherapists, and health researchers in general. The structure can be modulated and adapted to a variety of arts-based methods and approaches. The short written notes we used in our example can be exchanged with other expressions of the response art method (Chilton, Gerber, Councill, \& Dreyer, 2015). The method can be used at several steps in the research process (Chilton et al., 2015; Gerge, 2016; Leavy, 2015) and be helpful when developing rich and expressive findings (Ledger \& Edwards, 2011).

From an expressive arts perspective Shaun McNiff (1986, 1992, 1998, 2008, 2011, 2013) has highlighted the artistic endeavour in the aesthetic response as an essential part of ABR. The perspectives we bring to the Rx6 method are grounded in our own professional trainings (visual arts and music), however we consider that one of the major strengths of this method is that the researcher does not need formal training in the arts. It simply involves the capacity to be open and take in what is the focus of attention; that is enough.

\section{Implementation of the ABR-method Rx6}

The tradition of viewing, describing and researching artifacts produced in a therapeutic context by ABR seemed well suited and aligned with our pre-understandings as psychodynamically oriented psychotherapists, expressive arts therapists, art therapist (Anna Gerge) and music therapists, including GIM (Margareta Wärja and Inge Nygaard Pedersen). In the present study, applying the Rx6 method, we used paintings/drawings produced by research participants. These pictures were aesthetic responses/expressions of the subjects' on-going rehabilitation processes and life-worlds after treatment for gynaecological cancer before and after participating in a randomized controlled trial with an arts-based intervention (Wärja et al., 2012).

We, (AG and MW) decided to write short aesthetic responses to the artworks done as an avenue to conceptualize, deepen, and expand the tacit understanding of this material. The procedure was carried out in the structured manner of the Rx6-method. This arts-based inquiry was one part of a larger overarching qualitative research process within a mixed methods study. In applying the Rx6-method we followed six steps:

Step 1: Relate to the drawing/painting, as if the viewer "were" the produced image (i.e. change role with the image).

Step 2: Resonate an immediate embodied felt sense. The embodied felt sense is defined in line with the description by Gendlin (1978) as a bodily sensed knowledge, which he called a "felt sense."

Step 3: Respond from that embodied experience by writing a short text-note (aesthetic response).

Step 4: Reflect together and individually to gain a deepened understanding of the researched phenomena, discoveries, and findings.

Step 5: Results are acknowledged as expanded and deepened perspectives. Further informed ways to present and integrate these discoveries are searched for.

Step 6: React with this new knowledge. On a general level the Rx6-method, and other ABR approaches can lead to a more informed lived experience related the inquired phenomena. This can unleash new ways to encompass reality and - to react. 
The steps relate, resonate, respond, and reflect represent a fine-tuning, layering process that can be implemented in relation to a research topic. In this example of responding to the research participants' pictorial artifacts, we chose written statements. The whole procedure of each aesthetic response took about one minute. First taking in the image as a felt sense experience, responding to it by jotting down a few sentences on a post-it note, and then sticking it to the back of each painting. Certainly, in artsbased research it is possible to respond with various art expressions - images, sounds, rhythms, music and/or movements - that emerge in the felt sense of the responder. After the initial response, one can proceed by responding in one or more of the modalities or transfer to other art-forms, for example "answer" with a new drawing/painting to a done drawing/painting (Gerge, 2016) or by a performance piece.

The Rx6-method can be conceptualized as an adaptation to the heuristic research process (Moustakas, 1994; Schenstead, 2012), which includes: Initial engagement and Immersion - the researcher is involved in the world of experience; Incubation a space for awareness and trusting tacit knowledge (insights and understanding), including delving into the implicit domain, Illumination - an active knowing process to expand the understanding of the experience. This phase includes finding and feeling what is essential by staying immersed with the data until a new meaning arrives, Explication reflective actions, and finally the Creative Synthesis - bringing together the phenomena to show the patterns and relationships. All through this process it is important that the researcher reflects on the internal frame of reference, practices in keeping one's own personal context in mind, and tries to understand how this personal domain might influence the experience of the phenomena.

\section{Phases of Heuristic Research}

- Initial Engagement "The question lingers within the researcher and awaits the disciplined commitment that will reveal its underlying meanings" (Moustakas, 1990, p. 26). The search involves intuition and self-dialogue, and partly takes place in the realm of tacit knowledge.

- Immersion Living the question in waking, sleeping/dreaming, (Moustakas, 1990, p. 28). Self-dialogues where the researcher delves into the subject are used in a reflective manner. Our reflection, we consider the aesthetic response as a crucial tool in these processes.

- Incubation refers to a state where the researcher detaches her/himself from direct involvement with the inquiry. However, "on another level, expansion of knowledge is taking place" (Moustakas, 1990, p. 29), and new answers can arise, seemingly out of nothing, when the researcher is engaged in something else.

- Illumination the Eureka!-state is described as a realization "which occurs naturally when the researcher is open to tacit knowledge and intuition" (Moustakas, 1990, p. 29). When this "breakthrough in conscious awareness occurs, the researcher is awakened to a new dimension of knowledge or a modification of an old understanding" (Moustakas, 1990, p. 29).

- Explication involves explaining the meaning behind the changed perception, according to Schenstead (2012) "sifting through the layers of the data, using more self-searching, focussing, and in-dwelling" (para. 9). Core themes are created (Moustakas, 1990, p. 30-31). By turning back to previous stages of the research process links and patterns connecting to the present understanding can be found and provide new perspectives and understandings.

- Creative Synthesis involves bringing the themes together and describing the entire experience/phenomena. This process is heavily based on information of the implicit domain. The creative synthesis cannot be forced. Meditation, intuition, and self-search will bring it further (Moustakas, 1990, p. 31), as will involvement in arts experiences - both expressive and receptive avenues.

In Table 1 below, we bring an overview of the thematic structure of Rx 6 also related to the phases of heuristic research described above. 
Table 1. Schematic structure for ABR - Rx6 with Response Art as a Poetic Inquiry.

\begin{tabular}{|c|c|c|c|}
\hline State of the ABR in Rx6-method & Questions asked & Our example & $\begin{array}{l}\text { Relation to } \\
\text { the phases of } \\
\text { heuristic } \\
\text { research }\end{array}$ \\
\hline $\begin{array}{l}\text { RELATE: Engage with the phenomenon, } \\
\text { taking in the whole gestalt. Looking at } \\
\text { it, with an open to positive stance, giv- } \\
\text { ing space to the experience. }\end{array}$ & $\begin{array}{l}\text { What is this? If I become this } \\
\text { (painting) - what experience } \\
\text { emerges in me? }\end{array}$ & $\begin{array}{l}\text { The image/pictorial artifact was related to as } \\
\text { a whole story - a narrative or a world in itself } \\
\text { - a place for an emerging story. }\end{array}$ & $\begin{array}{l}\text { Initial engage- } \\
\text { ment }\end{array}$ \\
\hline $\begin{array}{l}\text { RESPOND I: Dialogue with the aesthetic } \\
\text { experience itself, "becoming" the im- } \\
\text { age, changing role with the inquired } \\
\text { content (here paintings), and allowing } \\
\text { "it" to speak. The essence could be } \\
\text { written in words or danced, sung/ } \\
\text { played or painted. }\end{array}$ & $\begin{array}{l}\text { What do I experience, what } \\
\text { do I sense? What do I feel } \\
\text { becoming the image? Going } \\
\text { back, out of role. How will I } \\
\text { respond now? What do I } \\
\text { want to respond with? What } \\
\text { do I do (write, paint, gestalt, } \\
\text { play, dance, say etc.)? }\end{array}$ & $\begin{array}{l}\text { Responding in a written statement took up to } \\
\text { one minute when putting down a few sen- } \\
\text { tences on a post-it note, and stuck it to the } \\
\text { back of the painting. A central aspect in the } \\
\text { responding process was the moment of meet- } \\
\text { ing, (MoM) (Sander, 2002; Stern, 2004). }\end{array}$ & $\begin{array}{l}\text { Immersion } \\
\text { and incuba- } \\
\text { tion }\end{array}$ \\
\hline $\begin{array}{l}\text { RESPOND II: When having performed } \\
\text { the initial aesthetic responses, a meta- } \\
\text { level of ABR - a crystallization process } \\
\text { - of the experience by responding to } \\
\text { the painting/drawings in the above- } \\
\text { mentioned way is used. This process } \\
\text { also encompasses the individual re- } \\
\text { flection of the next step. }\end{array}$ & $\begin{array}{l}\text { Having done this, what is } \\
\text { now emerging in me - what } \\
\text { is my answer to this experi- } \\
\text { ence? }\end{array}$ & $\begin{array}{l}\text { Our focus had a certain interest on the post- } \\
\text { test images, and the processes of change that } \\
\text { we registered. } \\
\text { A somewhat longer text (a half page) was } \\
\text { written by each of us as a condensation of } \\
\text { what we had experienced so far. }\end{array}$ & $\begin{array}{l}\text { Incubation } \\
\text { and explica- } \\
\text { tion }\end{array}$ \\
\hline $\begin{array}{l}\text { REFLECT: together and individually in } \\
\text { order to gain a deeper understanding } \\
\text { of the researched phenomenona, the } \\
\text { discoveries and findings. }\end{array}$ & $\begin{array}{l}\text { How does this make me } \\
\text { sense? What do I/we know } \\
\text { now, that I/we didn't know } \\
\text { before? }\end{array}$ & $\begin{array}{l}\text { We shared our texts, discussed our experi- } \\
\text { ences and the new pathways that opened up } \\
\text { into the material (see below). }\end{array}$ & $\begin{array}{l}\text { Explication } \\
\text { and beginning } \\
\text { creative syn- } \\
\text { thesis of the } \\
\text { felt sense ex- } \\
\text { perience }\end{array}$ \\
\hline $\begin{array}{l}\text { RESULTS: helping to find pathways in } \\
\text { the material. }\end{array}$ & $\begin{array}{l}\text { What is the best way to as- } \\
\text { similate and apply this new } \\
\text { or condensed knowledge? }\end{array}$ & $\begin{array}{l}\text { We realized through the process of ABR that } \\
\text { the pictorial artifacts contained richer infor- } \\
\text { mation in terms of affect, compared with the } \\
\text { written texts. Thus we could add shades to } \\
\text { the qualitative analyses of the texts produced } \\
\text { by participants. The Rx } 6 \text { was a fertilizing } \\
\text { starting point in developing an assessment } \\
\text { tool of pictorial artifacts. }\end{array}$ & $\begin{array}{l}\text { Creative syn- } \\
\text { thesis, and } \\
\text { how this im- } \\
\text { pacts what } \\
\text { will be per- } \\
\text { ceived and } \\
\text { thus commu- } \\
\text { nicable }\end{array}$ \\
\hline $\begin{array}{l}\text { REACT: with this new knowledge. Thus } \\
\text { making the ABR in an over-arching ac- } \\
\text { tion-oriented research-tradition } \\
\text { (Leavy, 2015). }\end{array}$ & $\begin{array}{l}\text { What is the best way to as- } \\
\text { similate and apply this new } \\
\text { or condensed knowledge? }\end{array}$ & $\begin{array}{l}\text { We were strengthened in considering } 1 \text { and } 2 \\
\text { as important: } \\
\text { 1. Augmented strategies in rehabilitation- } \\
\text { medicine, aimed at enhanced quality of life } \\
\text { (QoL) in oncology. } \\
\text { 2.The innate value of ABR and the } \\
\text { Rx6-method-protocol was an important } \\
\text { process to share. }\end{array}$ & $\begin{array}{l}\text { Creative Syn- } \\
\text { thesis in } \\
\text { thought and } \\
\text { action, in- } \\
\text { formed by an } \\
\text { embodied } \\
\text { (new) knowl- } \\
\text { edge }\end{array}$ \\
\hline
\end{tabular}




\section{Researching Artifacts with ABR - Rx6}

\section{The Procedure of Implementing Rx6}

The following is a detailed step-by-step description of the Rx6-method using the example of written notes as responses to art created by research participants. The short condensed texts were easily administrated and handled, yet holding the aesthetic experience and immersion of a given moment (bare consciousness). Words are descriptive and can hold multiple meanings, and symbolic contents, especially in metaphors (Barone \& Eisner, 2012; Lakoff \& Johnson, 1980/2003, 1999).

\section{Relating and Resonating with the Researched Phenomena}

The focus of our inquiry was to understand developmental processes of women being treated for gynaecological cancer as revealed in their artwork. An approach, called KMR, Brief-Music Journeys (Korta musikresor) (Wärja, 2010) based in the tradition of Guided Imagery and Music (GIM), was chosen for the intervention. It involves listening to pre-selected short pieces of music of varying dynamic intensity (Wärja \& Bonde, 2014), which lasted between 3 to 5 minutes, followed by an art-making experience, and a reflective phase around the music experience. Here the method was meant to evoke images and life-themes connected to cancer (Wärja, 2012a, 2012b, 2015). Wärja (principal investigator of the intervention study) collected pictures and texts, where the participants' responses to their body images were gathered at three times: baseline, post-test, and follow-up after 7 months. At follow-up only paintings from the participants in the individual treatment arm were gathered. The information provided each time was, "Paint a picture quite freely and spontaneously about the experience of your body today, after illness and after cancer treatments. How do you see your body? How does it feel? How do you experience your body? After the painting was completed a similar instruction was given for writing a free and spontaneous text.

Short response statements were individually jotted down on Post-it ${ }^{\circledR}$ note $(7,5 \mathrm{~cm}$ $\mathrm{x} 7,5 \mathrm{~cm})$ by the first two authors. The statements were placed on the back of each painting. In the first step all pictorial artifacts from baseline were analysed through ABR $(n=57)$ to be followed by artifacts collected at post-test $(n=45)$, and concluded with the analysis of images from follow-up $(n=15)$. At follow-up only pictures from the individual treatment arm was collected. During the next step, we placed the paintings from baseline and post-test next to each other. This opened to a viewing and taking in a new combined picture, where the two pictures were "speaking to each other". We noted changes and differences and gave room for a response. As researchers we were well aware of the therapeutic intervention that had taken place between measurements. This was most likely the case for the research participants, however at the time of data collection previous pictures were not shown. In particular, we focused on what we perceived as the change process that had taken place between the images, which was hypothesized to be an effect of the intervention. We then proceeded by adding the paintings from follow-up, thus having three images lined up $(n=15)$. The responding process continued until all sequences of pictorial artifacts had been worked through. In our case we worked through in total 117 pictorial artifacts. The brief written statements, used as response art, can be described as essences of immediate, spontaneous, and embodied words. The ABR process involved dialoguing with the image and inviting the possibility of surprise and emotional resonance.

\section{Responding and reflecting the Poetic Inquiry}

When the cycle of steps and processes of aesthetic responses were followed through, a corroboration of ABR had been completed. This arts-based inquiry had a particular focus on the developmental progress between pre- and post-test images. As a final piece we thus, as a corroboration, let the multiple pieces of artistic data (the raw data) come together in a compelling whole. MW and AG composed a spontaneous free text as a 
condensation of what we had just experienced. This was done both to make a closure and to potentially increase the validity of the inquiry.

Life has returned. There is a resurrection.

Now my body has contours and boundaries.

I am alive!

I will celebrate.

This rite of passage is like crossing the dessert, and finding a well...

From that source I drink faith in life, and belief in love.

Oh! Come on, more desire, sensuality and sexuality!

I am strong. Feel empowered. I want to live.

I belong to the world. I am more healed now.

Transformation.

Healing.

Integration.

Embodiment.

Grounding.

Here I am.

It's like a frostbitten continent wakes

and rises in bloom

Inanna rises

The horror frozen inner children

reach out to the world

become women with dancing souls

and bodies

It is a miracle - like seeing

bird Phoenix hatch and do not burn

but instead become a female being

with soft steps

in a world that is holding

holds hope

and is the body

\section{Results and React}

We found the Rx6 method helpful in carving out categories to be used in further analyses around body image connected to gynaecological cancer. (Results leading to React). We consider, in line with Viega (2016b), that art as a primary method in research can add to a deepened understanding. The emotional difficulties and existential exposure of women with a history of gynaecological cancer became explicit when encountering their artwork with an ABR stance. ABR energized us in the research process. It seemed evident, that even if the medical cancer treatments were completed, the psychosocial, sexual, and existential health of the research participants could still be improved (Juraskova et al., 2003, Steele \& Fitch, 2008).

The pictorial artifacts produced by the research participants opened to a more profound understanding of the affective quality of their felt sense experience (Gendlin, 1964, 1978), such as being vulnerable, angry, and afraid. This new pre-understanding could be brought into further reflections and could sharpen the qualitative analyses to be conducted. Albeit the art was not used as an adjunctive method in research but could also have been conducted in this way.

\section{Discussion}

Ten years ago, Austin and Forinash (2005) stated the artistic processes could provide information at each step of the research study that is unique and is not knowable by other means. They highlighted ABR as central and essential to the research process and stated the certain value of ABR methods in reflecting the experiences of the research 
subjects be it practitioners or patients. Austin and Forinash also invited ABR to be a bigger part of the research field of music therapy as "arts-based research has not been widely used in music therapy" (p. 460). Recently a renewed interest for arts-based research in the music therapy research tradition is documented (Edwards, 2015; Kenny, 2015; Ledger \& McCaffrey, 2015; McCaffrey \& Edwards, 2015; Schenstead, 2012; Viega, 2016a, 2016b). However, there are some problems adhering this method.

Ledger and Edwards (2011) stated, "The lack of engagement in arts-based approaches by music therapists could be regarded as a missed opportunity to develop further methods that are highly suitable for studying aspects of music therapy practice" (p. 315). Further Ledger and Edwards discussed that "it might be that in arts-based research, the distinctions between professional practice and research are not delineated enough to satisfy music therapy practitioners, that they are engaged in research rather than art production" (p. 315). This can of course also apply to other art therapists and needs to be further discussed (Gerge, 2016). Recently, Edwards (2015) pointed to the social status of anxiety in music therapy as a restricting factor of applying ABR. Ledger and Edwards (2011) proposed that further uses of ABR could give voices to people who receive music therapy services and communicate music therapy research findings. This can happen both intra-disciplinary and interdisciplinary.

We ought to ask ourselves "what was learned in the ABR process that otherwise would have been left out?" If the answer is nothing, we do not need to do ABR, we can stick to other research methods. However, if we think ABR can add a certain value, maybe even new ways to see, encompass, conceptualize and react to aspects of human life - we can consciously invite ourselves into the "third space" where the objective and the subjective meet according to Sava and Nuutinen (2003, p. 532). This "third place" is supposed to emerge when art and inquiry, image and word meet. This space is seen as: strongly experiential, sensory-based, multi-interpretive like a fleeting shadow, intuitive and ever changing, (p. 532), i.e. in line with implicit functioning which can hold multiple meanings at once. A supporting evidence for working with applied artistic methods in the aesthetics-improvisation-method realm was given within the critical discussion of Sajnani, Marxen, and Zarate (2017). They described the artistic experience/expression as a gateway to psychic spaces beyond boundaries, as did Wiedenhofer (2017).

In our case, the preconceptions needed to be clarified; we decided to look for change between before and after intervention. As psychotherapists we were interested in finding ways to discern if the therapeutic process had provided a difference that we could resonate with and then describe in a few words. Maybe some other readings of the artifacts would have been just as true; albeit the similarities in our aesthetic responses can be seen as an internal validity. Although the generalizability of the results of an ABR inquiry is unclear, the same applies to comparability. The aesthetic response of artifact A is what it is, and how this can be transferred to artifacts B, C, D, etc. - or other populations, other researchers and/or modalities - it is still a growing field of knowledge.

The risk of becoming too subjective is a caveat in ABR. When inquiring how art therapists made meaning from viewing art produced by clients, Curtis (2011) stated: "personal associations helped refine meaning, rather than distract from it" (p. 5). Maybe some knowledge has to be "subjectified" to become available?

\section{Benefits of $A B R$}

To conclude we will highlight some general advances of the ABR-approach:

\section{Deepened understanding}

ABR can be a complement to quantitative or qualitative research, or provide another avenue of conducting research (Viega, 2016b). It can add considerably to a process of inquiry or it can stand alone (Gerge, 2016; Kenny, 2015). ABR practices may be valuable when a researcher or a team wish to develop a close collaboration with other par- 


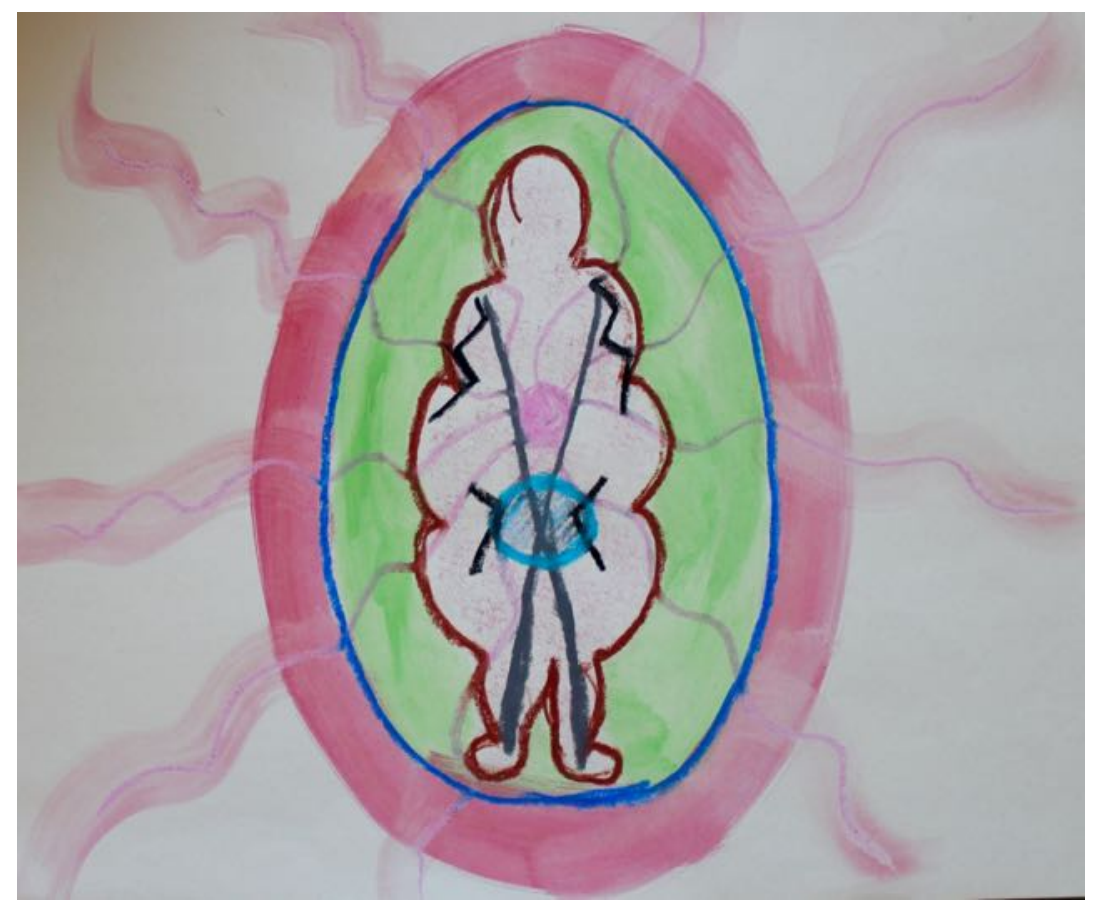

Figure 2. Client picture before treatment

AG: They strapped me. They made me mushy.

MW: I'm stuck. Encapsulated in an egg. Have to stand it. Have to become better. Aching, feel ungaingly. Without identity. Branded.

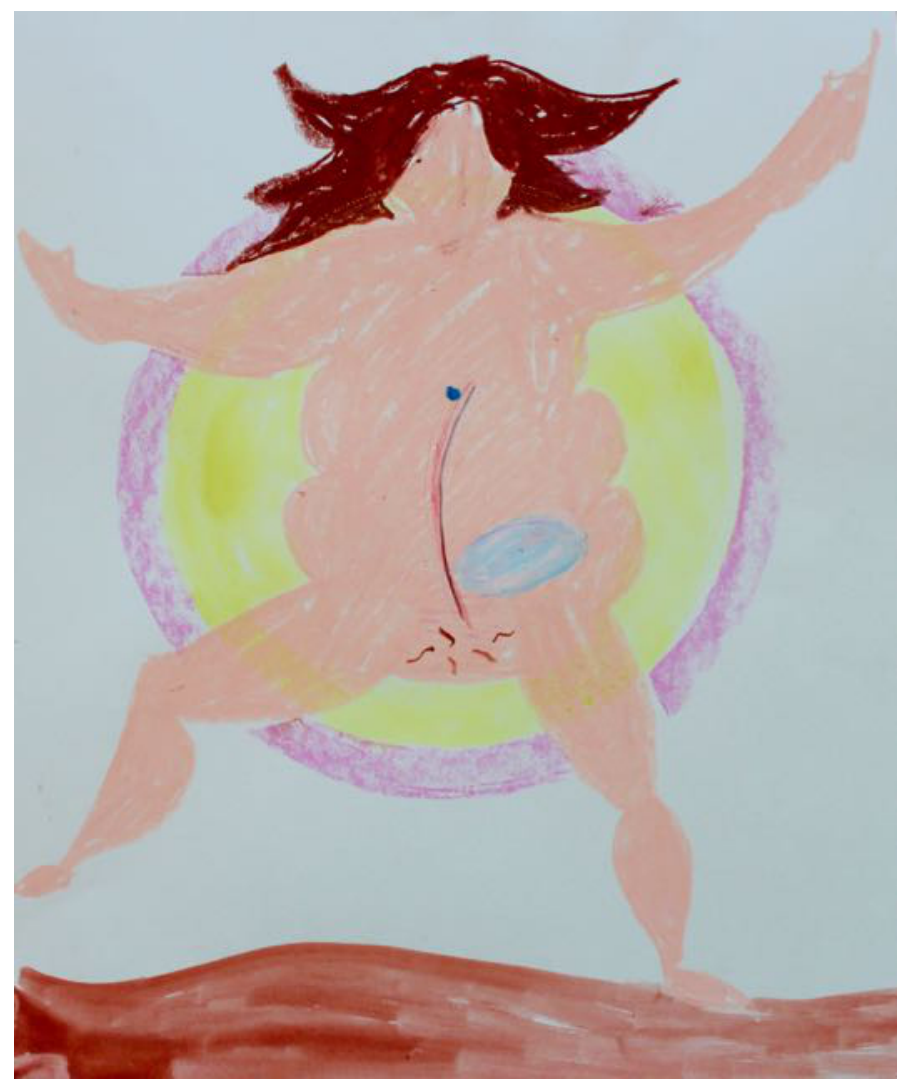

Figure 3. Client picture after treatment

AG: I can dance on the earth - yes, I am scarred, but I am a real woman - soon I will find my genitals! MW: I am here! Reborn. Happy and proud. Released from my prison. Scarred, with a weight in my womb. But true. Maybe soon I will dare to see, and peek out. 


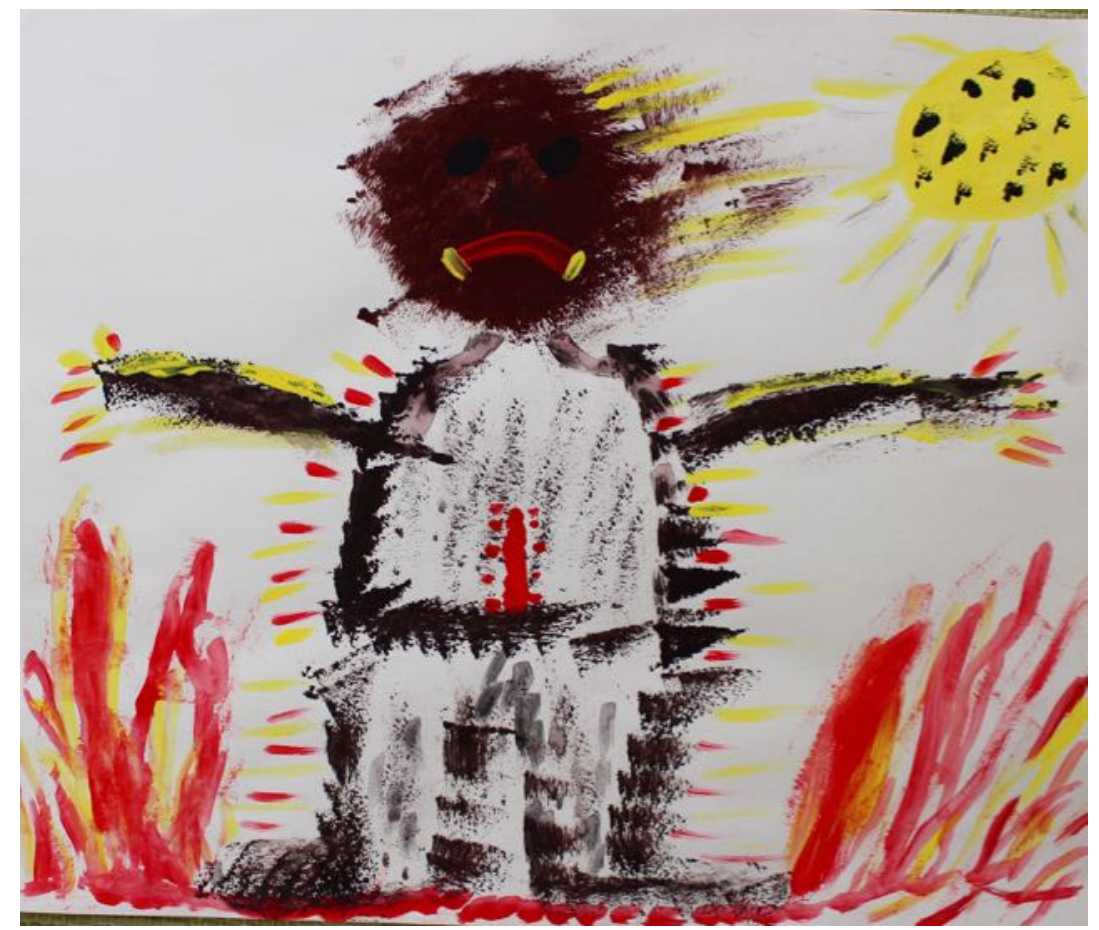

Figure 4. Client picture before treatment

AG: They have cut me in pieces. The soil is burning, and even the sun is blackened. I am standing in the middle of this.

MW: I am angry! Enraged at life! And scared! It is the solar eclipse. The day of wrath. I must fight!

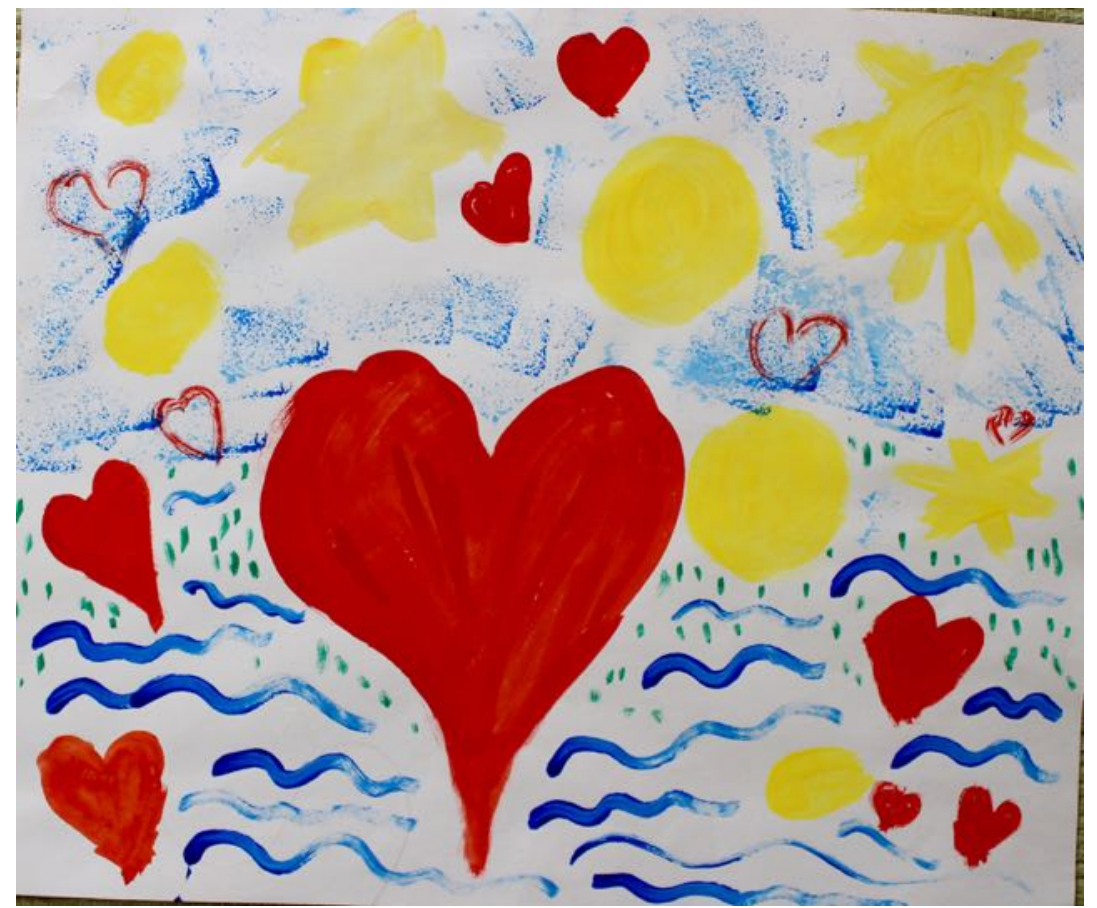

Figure 5. Client picture after treatment

AG: The fire is out and my heart can rest in the world. It bumps around a bit on the nice waves.

MW: I am no longer angry. I embrace life. Love has triumphed. I am resurrected. All the powers of nature carry me. I have faith and trust! 
ticipants in the research according to Vaillancourt (2011). The ABR-experience, in our case, opened up to shared creativity and tenderness. We could clearly see the compassion and interest of each other when relating to the artifacts produced by the research participants. We were struck by the similarities in our aesthetic responses, see examples in figures 2, 3, 4 and 5, where 2 and 4 were before treatment, and 3 and 5 were after treatment. One informant created figures 2 and 3 and another informant created 4 and 5. We know "no (wo)man is an island", but the remembrance of our shared vulnerability and livelihood touched us. We consider the arts-based format crucial for this.

\section{Deepened compassion}

Finally, a central aspect of the psychotherapeutic undertaking of conducting research on health related issues concerns the deepened capacity to stay in touch with the lifeworlds of those who suffer - the patients, the clients, the participants. We think ABR can enhance joint research endeavours and - performed with creativity and tenderness - can open up new understandings of the researched participants' life-worlds. ABR can provide structured and creative ways of being in contact, and grow in empathy with the informants. We propose that ABR can be used as a valuable tool in training programs aimed towards the helping professions. In addition, ABR can be utilized as a form of self-care and self-supervision.

\section{Conclusion}

According to Edwards' (2015) introduction to the special issue on the arts-based inquiry in the Journal of Music Therapy, she stated that this approach "has received minimal exposure in music therapy to date" (p. 437) and that more ABR studies are asked for (McCaffrey \& Edwards, 2015). Also Viega (2016b) noted this lack of research "[A] modest amount of ABR research has been published in music therapy" (p. 5).

The ABR processing of data is linked to heuristic research as the researcher continues to immerse him/herself within the topic or phenomenon until a new understanding (illumination) occurs. ABR emphasizes an artistic response to the raw data (interview, music, art piece, etc.) as part of the data-generating process. The process of knowing in $A B R$ is close to the everyday action research of clinical work, where being together with the client offers growing tacit knowing, in line with the heuristic spiral. Especially psychotherapists trained in the arts and using altered states of consciousness, have a solid understanding of sharing implicit processes and tacit knowledge with their patients. From our perspective ABR is not about doing "art", but about using the rich sources from where the aesthetic response rises, together with artistic tools to understand aspects of being human in new and more profound ways. When adding ABR, both as a methodology and as a method, the clinician/researcher allows herself to use her/his own experience of the phenomena as a source of information about the other in line with contemporary neuroscience and attachment theory (Ammaniti \& Gallese, 2014).

Nonetheless, we consider the method proposed in this text to be an easy approach to use for clinicians and researchers as well. It is possible that a limited experience with the various art forms and of intermodal transfer, as applied in expressive arts therapy, might be experienced as a restricting factor when starting out applying ABR. We acknowledge that our 25 years of experiences in practicing and teaching arts-based approaches based on applying intermodal transfer under the paradigm of expressive arts therapy, (Estrella, 2005; Gerge, Ranch, \& Rudstam, 2010; Levine \& Levine et al., 1998, 2005; Wärja 2010, 2012a, 2012b) have contributed and influenced our preunderstandings in conducting ABR. Although, we propose that a strength of the Rx6 method is that it is "user-friendly" to newcomers to the field and that artistic training is not a pre-requisite. The method is grounded on a theoretical framework (Creswell, 2009) of inter-subjectivity and implicit processing based on attachment research and contemporary neuroscience. These innate processes are seen as interwoven with our 
narrating potential, and thus constructing our capacity to mentalize (Fonagy \& Luyten, 2015), and coming close, paraphrasing the words of Stern (2004) "one can not get to the lived experience and stay there while talking about it. But that does not stop me from thinking about it and approaching as close as I can" (p. xiii).

\section{References}

Ammaniti, M., \& Gallese, V. (2014). The birth of intersubjectivity - Psychodynamics, neurobiology, and the self. New York: WW Norton \& Co.

Austin, D., \& Forinash, M. (2005). Arts-based research. In B. Wheeler (Ed.), Music therapy research (2nd ed., pp. 458-471). Gilsum, NH: Barcelona.

Barone, T., \& Eisner, E. (2012). The arts and psychotherapy. Los Angeles, CA: Sage Thomas.

Chilton, G., Gerber, N., Councill, T., \& Dreyer, M. (2015). I followed the butterflies: Poetry of positive emotions in art therapy research. Cogent Arts \& Humanities, 2(1), 1026019, http://dx.doi.org/10.1080/23311983.2015.1026019.

Cozolino, L. (2002/2010). The neuroscience of psychotherapy. Building and rebuilding the human brain. New York, NY: Norton.

Creswell, J. W. (2009). Research design: Qualitative, quantitative and mixed methods approaches (3rd ed.). Thousand Oaks, CA: Sage.

Curtis, E. K. (2011). Understanding client imagery in art therapy. Journal of Clinical Art Therapy, 1(1), 9-15, http://digitalcommons.lmu.edu/jcat/vol1/iss1/6.

Douglass, B., \& Moustakas, C. (1985). Heuristic inquiry: The internal search to know. Journal of Humanistic Psychology, 25(3), 39-55, https://doi.org/10.1177/0022167885253004.

Edwards, J. (2015). Getting messy: Playing, and engaging the creative, within research inquiry. Journal of Music Therapy, 52(4), 437-440, https://doi.org/10.1093/jmt/thv015.

Estrella, K. (2005). Expressive therapy: An integrated arts approach. In C. A. Malchiodi (Ed.), Expressive therapies (pp. 183-209). New York: Guilford Press.

Fonagy, P., \& Luyten, P. (2015). A multilevel perspective on the development of borderline personality disorder. In D. Cicchetti (Ed.), Developmental psychopathology. Vol 3: Maladaptation and psychopathology (pp. 726-792).

Forinash, M. (2016). On supervising arts-based research. Music Therapy Perspectives, 34(1), 41-45, http://dx.doi.org/10.1093/mtp/miv048.

Gallese, V. (2009). Mirror Neurons, Embodied Simulation, and the Neural Basis of Social Identification. Psychoanalytic Dialogues, 19(5), 519-536, http://dx.doi.org/10.1080/ 10481880903231910.

Gallese, V., \& Ferri, F. (2014). Psychopathology of the Bodily Self and the Brain: The Case of Schizophrenia. Psychopathology, 47(6), 357-364, https://doi.org/10.1159/000365638.

Gendlin, E. T. (1964). A theory of personality change. In P. Worchel \& D. Byrne (Eds.), Personality change (pp. 100-148). New York: John Wiley and Sons.

Gendlin, E. (1978). Focusing. New York, NY: Everest House.

Gerge, A. (2010). Kreativt gestaltande psykoterapi. [Creative psychotherapy]. In A. Gerge, M. Ranch, \& G. Rudstam (Eds.), Kreativt gestaltande psykoterapi (pp. 16-116). Stockholm: Insidan.

Gerge, A. (2016). Answering from the centre: Arts-based research for knowing more. Manuscript submitted for publication.

Gerge, A., Wärja, M., \& Pedersen, I. N. (2017). Using Aesthetic response, a poetic inquiry to expand knowing. Part II: Some theoretical perspectives on arts-based research. Voices: A World Forum for Music Therapy, 17(1), http://dx.doi.org/10.15845/voices.v17i1.913.

Gilroy, A. (2012). What's best for whom? Exploring the evidence base for assessment in art therapy. In A. Gilroy, R. Tipple, \& C. Brown (Eds.), Assessment in art therapy (pp. 11-27). New York, NY: Routledge. 
Juraskova, I., Butow, P., Robertson, R., Sharpe, L., McLeod, C., \& Hacker, N. (2003). Posttreatment sexual adjustment following cervical and endometrial cancer: a qualitative insight. Psycho-oncology, 12(3), 267-279, http://dx.doi.org/10.1002/pon.639.

Kenny, C. (2015). Performing theory: Playing in the music therapy discourse. Journal of Music Therapy, 52, 457-486, http://dx.doi.org/10.1093/jmt/thv019.

Knill, P., Barbra, H., \& Fuchs, M. (1995). Minstrels of the soul. Toronto: Palmerston.

Knill, S. K. (2004). Principles and practice of expressive arts therapy : Toward a therapeutic aesthetics. London: Jessica Kingsley Publishers.

Lakoff, G., \& Johnson, M. (2003). Metaphors we live by. Chicago, IL: University of Chicago Press. https://doi.org/10.7208/chicago/9780226470993.001.0001.

Lakoff, G., \& Johnson, M. (1999). Philosophy in the flesh. Chicago, IL: University of Chicago Press.

Ledger, A. J., \& Edwards, J. (2011). Arts-based research practices in music therapy research: Existing and potential developments. Arts in Psychotherapy, 38, 312-317, https://doi.org/ 10.1016/j.aip.2011.09.001.

Ledger, A., \& McCaffrey, T. (2015). Performative, arts-based, or arts-informed? Reflections on the development of arts-based research in music therapy. Journal of Music Therapy, 52, 441-456, https://doi.org/10.1093/jmt/thv013.

Leavy, P. (2009). Method meets art: Arts-based research practice. New York: Guilford Press.

Leavy, P. (2015). Method meets art: Arts-based research practice (2nd ed.). New York, NY: Guilford Press.

LeDoux, J. (1996). The emotional brain. New York, NY: Simon \& Schuster.

Levine, E., \& Levine, S. K. (Eds.). (1998). Foundations of expressive arts therapy: Theoretical and clinical perspectives. London, England: Jessica Kingsley Publishers.

Levine, K., \& Levine, E. (2005). Principles and practice of expressive arts therapy. towards a therapeutic aesthetics. London, England: Jessica Kingsley Publishers.

Lyons-Ruth, K. (1999). The two-person unconscious: Intersubjective dialogue, enactive relational representation, and the emergence of new forms of relational organization. Psychoanalytic Inquiry, 19, 576-617, https://doi.org/10.1080/07351699909534267.

Lyons-Ruth, K., Bruschweiler-Stern, N., Harrison, A. M., Morgan, A. C., Nahum, J. P., Sander, L., Stern, D. N., \& Tronick, E. Z. (1998). , Implicit relational knowing: Its role in development and psychoanalytic treatment. Infant Mental Health Journal, 19, 282-289, http://dx.doi.org/10.1002/(SICI)1097-0355(199823)19:3<282::AID-IMHJ3 > 3.0.CO;2-O.

McCaffrey, T., \& Edwards, J. (2015). Meeting art with art: Arts based methods enhance researcher reflexivity in research with mental health service users. Journal of Music Therapy, 52, 515-532, https://doi.org/10.1093/jmt/thv016.

McNiff, S. (1986). Freedom of research and artistic inquiry. Arts in Psychotherapy, 13, 279-284, https://doi.org/10.1016/0197-4556\%2886\%2990028-6.

McNiff, S. (1992). Art as medicine: Creating a therapy of the imagination. Boston \& London: Shambala.

McNiff, S. (1998). Art-based Research. London: Jessica Kingsley.

McNiff, S. (2008). Art-based research. In J. G. Knowles \& A. L. Cole (Eds.), Handbook of the arts in qualitative research: Perspectives, methodologies, examples, and issues. Thousand Oaks, CA: Sage Publications. https://doi.org/10.4135/9781452226545.n3.

McNiff, S. (2011). Artistic expressions as primary modes of inquiry. British Journal of Guidance \& Counselling, 39(5), 385-396, https://doi.org/10.1080/03069885.2011.621526.

McNiff, S. (2013). Art as research opportunities and challenges. Chicago, IL: Intellect.

Moustakas, C. (1990). Heuristic research: Design, methodology, and applications. Thousand Oaks, CA: Sage. https://doi.org/10.4135/9781412995641.

Moustakas, C. (1994). Phenomenological research methods. Oaks, CA: Sage. https://doi.org/ $10.4135 / 9781412995658$. 
Polanyi, M. (1958). Personal knowledge. Towards a post critical philosophy. London, England: Routledge.

Rolling, J. H. (2013). Arts-based research primer. NY: Peter Lang. https://doi.org/10.3726/ 978-1-4539-1086-3.

Sajnani, N., Marxen, E., \& Zarate, R. (2017). Critical perspectives in the arts therapies: Response/ability across a continuum of practice. The Arts in Psychotherapy, https://doi.org/ 10.1016/j.aip.2017.01.007.

Sander, L. W. (2002). Thinking differently: Principles of process in living systems and the specificity of being known. Psychoanalytic Dialogues, 12, 11-42, https://doi.org/10.1080/ 10481881209348652.

Sava, I., \& Nuutinen, K. (2003). At the meeting place of word and picture: Between art and inquiry. Qualitative Inquiry, 9(4), 515-535, https://doi.org/10.1177/1077800403254218.

Schenstead, A. R. (2012). The timelessness of arts-based research: Looking back upon a heuristic self-study and the arts-based reflexivity data analysis method. Voices, 12(1), http://dx.doi.org/10.15845/voices.v12i1.589.

Siegel, D. (2010). Mindsight: The new science of personal transformation. New York, NY: Norton.

Steele, R., \& Fitch, M. I. (2008). Supportive care needs of women with gynecologic cancer. Cancer Nursing, 31(4), 284-291, http://dx.doi.org/10.1097/01.NCC.0000305743.64452.30.

Stern, D. (2004). The present moment in psychotherapy and everyday life. New York: Basic Books.

Vaillancourt, G. (2011). Creating an apprenticeship music therapy model through arts-based research. Voices: A World Forum for Music Therapy, 11(1), https://doi.org/10.15845/ voices.v11i1.341.

Viega, M. (2016a). Aesthetic sense and sensibility: Arts-based research and music therapy. Music Therapy Perspectives, 34, 1-3, http://dx.doi.org/10.1093/mtp/miw010.

Viega, M. (2016b). Science as art: Axiology as a central component in methodology and evaluation of arts-based research (ABR). Music Therapy Perspectives, 34, 4-13, http://dx.doi.org/10.1093/mtp/miv043.

Viega, M., \& Forinash, M. (2016). Arts-based research. In B. L. Wheeler \& K. M. Murphy (Eds.), Music therapy research (pp. 491-504). Dallas, TX: Barcelona Publishers.

Wiedenhofer, S. (2017). Active factors in dance/movement therapy: Specifying health effects of non-goal-orientation in movement. The Arts in Psychotherapy, 52, 10-23, http://dx.doi.org/10.1016/j.aip.2016.09.004.

Wärja, M. (2010). Korta Musikresor (KMR). På väg mot en teori som musikterapeutisk metod. [Short music journeys. Towards a theory of KMR as music therapy method]. Stockholm, Sweden: Royal College of Music. , Unpublished master's thesis.

Wärja M. (2012a). Protocol for the group therapy intervention. KMR-Brief music journeys and expressive arts. A randomized controlled trial for women treated for gynecological cancer. Unpublished manuscript, Faculty of the Humanities, Aalborg University, Aalborg, Denmark.

Wärja M. (2012b). Protocol and guidelines for the individual therapy intervention KMR-brief music journeys and expressive arts. A randomized controlled trial for women treated for gynecological cancer. Unpublished manuscript, Faculty of the Humanities, Aalborg University, Aalborg, Denmark.

Wärja, M. (2015). Music therapy in expressive arts. In B. L. Wheeler (Ed.), Music therapy handbook (pp. 246-259). New York: Guilford Press.

Wärja, M., Bergmark, K., \& Bonde, L. O. (2012). Music and expressive arts therapy for women with a history of gynaecological cancer. Current Controlled Trials. http://www.controlledtrials.com, Assigned 03-04-2012.

Wärja, M., \& Bonde, L. O. (2014). Music as co-therapist: Towards a taxonomy of music in therapeutic music and imagery work. Music and Medicine, 6(2), 16-27. 